Original Article

\title{
EVALUATION OF DRUG THERAPY PROBLEMS IN ASTHMA PATIENTS RECEIVING CARE IN TWO HOSPITALS IN SOUTH-EASTERN NIGERIA
}

\section{KOSISOCHI CHINWENDU AMORHA**, ANTHONY CHUKWUMA ONU, CHIGOZIE GLORIA ANENE-OKEKE, CHINWE VICTORIA UKWE}

\author{
Kosisochi Chinwendu Amorha (B. Pharm, M. Pharm, FPC Pharm) \\ Email: kosisochi.amorha@unn.edu.ng
}

Received: 09 Jun 2017 Revised and Accepted: 21 Dec 2017

\author{
ABSTRACT \\ Objective: To evaluate drug therapy problems in asthma patients visiting a secondary and tertiary hospital in South-Eastern Nigeria.
}

Methods: This study was a retrospective, cross-sectional analyses of the medical records of adult asthmatic patients receiving care in two hospitals in Enugu State, within a 15-year period. The Pharmaceutical Network Care Europe (PCNE) tool version 6.2 was used to assess drug therapy problems. The IBM Statistical Product for Services Solution (SPSS) version 20.0 was used for analysis. For all results, P $\leq 0.05$ was considered statistically significant.

Results: Majority of the patients were below 60 y old (81.2\%); female (68.8\%) and were on more than two drugs (95.3\%). Majority of the identified drug therapy problems (DTPs) were adverse reactions (65.7\%). The inappropriate drug combination was the major cause of DTPs (65.6\%). Only about $23.4 \%$ of the intervention outcomes were known. University of Nigeria Teaching Hospital (UNTH) had more interventions (35.9\%) than Medical Centre $(8.0 \%)\left(\chi^{2}=6.323 ; \mathrm{df}=1 ; * * \mathrm{P}=0.012\right)$; and more of the outcomes of their interventions known (38.5\%) compared to Medical Centre $(0.0 \%)\left(\chi^{2}=12.559 ; \mathrm{df}=1 ; * * \mathrm{P}<0.001\right)$.

Conclusion: Adverse reactions and inappropriate drug selection were the major identified DTPs and major cause of DTPs, respectively. Most DTPs had no interventions. The documented interventions included stopping of the drugs, change of drugs or dosage, change of instructions for use and starting of new drugs. Most interventions had unknown outcomes. UNTH had more interventions with known outcomes than the University of Nigeria Medical Centre.

Keywords: Asthma, Drug therapy problems, Nigeria

(C) 2018 The Authors. Published by Innovare Academic Sciences Pvt Ltd. This is an open access article under the CC BY license (http://creativecommons.org/licenses/by/4.0/) DOI: http://dx.doi.org/10.22159/ijpps.2018v10i2.22472

\section{INTRODUCTION}

Asthma is a global health problem that imposes a substantial burden on patients, their families, and communities [1]. It affects an estimated 300 million individuals worldwide. Asthma affects all age groups, with increasing prevalence in many developing countries [2]. In Africa, there is a paucity of data concerning the management pattern and burden of asthma [3]. Asthma is a serious burden in low-and-middleincome countries [4]. According to the former National President of the Nigerian Thoracic Society; no fewer than 15 million Nigerians are suffering asthma, tuberculosis and other chest-related diseases [5]. This high number of Nigerians suffering from asthma and other chest diseases were attributed to lack of preventive measures. There is a high prevalence of asthma among Nigerian adolescents and adults compared with regional and global averages [6].

A drug therapy problem (DTP) is any undesirable event experienced by a patient that involves, or is suspected to involve drug therapy, and that interferes with achieving the desired goals of therapy and requires professional judgment to resolve [4]. DTPs are the clinical domain of the pharmaceutical care practitioner. The purpose of identifying drug therapy problems is to help patients achieve their goals of therapy and realize the best possible outcomes from drug therapy.

The objective of this study was to assess drug therapy problems among adult asthmatic patients' attending respiratory clinics in two hospitals in south-eastern Nigeria.

\section{MATERIALS AND METHODS}

Study design and study site

This study was a retrospective, cross-sectional analysis of the medical records of adult asthmatic patients receiving care in two hospitals in Enugu State, within a 15 y period (January 1, 2001 to December 31, 2015).

The University of Nigeria Teaching Hospital (UNTH), Ituku-Ozalla; a tertiary health institution and the University of Nigeria Medical Centre (UNMC); a secondary health institution were utilized for the study.

\section{Eligibility criteria}

The study population included the folders of all adult patients with confirmed diagnosed asthma within the study period (January 1 , 2001, to December 31, 2015); patients that were on asthma drug therapy within the study period; patients that were within the ages of 18 and above with available medical records. Only folders from UNTH and UNMC were utilized for the study.

\section{Data collection}

The data were collected from the patients` medical records using the Pharmaceutical Care Network Europe (PCNE) Classification tool Version 6.2 [7]. For each of the medical records, the DTPs experienced within $3 \mathrm{y}$ from discharge or within three $3 \mathrm{y}$ from last clinic visit were identified. The demographic information such as age and gender were recorded. Other data recorded were the drugs implicated in the therapy problems, type of DTP, the cause of DTP, type of intervention and the outcome of the intervention.

The PCNE V 6.2 has 4 primary domains for problems, 8 primary domains for causes and 5 primary domains for interventions. On a more detailed level, there are 9 grouped sub-domains for problems, 37 grouped sub-domains for causes and 17 grouped sub-domains for interventions. The sub-domains are explanatory for the principal domains. 


\section{Data analysis}

Data were entered and analyzed using the IBM Statistical Product for Services Solution (SPSS) Statistics for Windows, Version 20.0 (IBM Corp, Version 20.0, Armonk, NY, USA). Descriptive statistics were used to summarize data. The Pearson chi-square test was used, where applicable, to show the association between variables. For all results, $\mathrm{p}$-value $\leq 0.05$ was considered statistically significant.

\section{Ethical approval}

Ethical approval was obtained from the Health Research and Ethics Board committee of each hospital used for the survey (NHREC/05/01/2008B-FWA00002458-1RB00002323).

\section{RESULTS}

A total of 64 medical records of patients with confirmed diagnosis of asthma were reviewed and assessed for DTPs. More than half of the patients were below 60 y old $(52,81.2 \%)$, out of this 44 were female $(68.8 \%)$. About $95.3 \%$ of the patients were taking more than two drugs. See table 1 for more details.
Majority of the identified drug therapy problems were adverse reactions $(65.7 \%)$, fig. 1 .

The combination of artemether-lumefantrine and vitamin c, as well as aminophylline and hydrocortisone, were responsible for more than a quarter of the drug therapy problems, table 2.

Table 3 shows that inappropriate drug combinations were the major cause of drug therapy problem $(65.6 \%)$.

About three-quarter of the drug therapy problems had no documented interventions, table 4 .

Of the few interventions documented, only about $23.4 \%$ had known intervention outcomes, table 5 .

UNTH had more interventions (35.9\%) than Medical Centre (8.0\%), table 6.

UNTH had more of the outcomes of their interventions known (38.5\%) compared to Medical Centre (0.0\%), table 7.

Table 1: Demographic characteristics/drug details

\begin{tabular}{|c|c|}
\hline Variables & n (\%) \\
\hline \multicolumn{2}{|l|}{ Age } \\
\hline $18-29$ & $18(28.1)$ \\
\hline $30-39$ & $14(21.9)$ \\
\hline $40-59$ & $20(31.2)$ \\
\hline$\geq 60$ & $12(18.8)$ \\
\hline \multicolumn{2}{|l|}{ Gender } \\
\hline Male & $20(31.2)$ \\
\hline Female & $44(68.8)$ \\
\hline \multicolumn{2}{|l|}{ Type of Medicine } \\
\hline Prescription & $58(95.1)$ \\
\hline OTC & $3(4.9)$ \\
\hline \multicolumn{2}{|l|}{ Hospital Visit } \\
\hline New & $42(65.6)$ \\
\hline Refill & $22(34.4)$ \\
\hline \multicolumn{2}{|c|}{ Number of Drugs Taken } \\
\hline $0-2$ & $3(4.7)$ \\
\hline $3-6$ & $34(53.1)$ \\
\hline$\geq 7$ & $27(42.2)$ \\
\hline \multicolumn{2}{|l|}{ Institution } \\
\hline UNTH & $39(60.9)$ \\
\hline UNN Medical Centre & $25(39.1)$ \\
\hline
\end{tabular}

Table 2: Drugs involved with the identified drug therapy problems

\begin{tabular}{|c|c|c|}
\hline Name of medication & Drug therapy problem & n (\%) \\
\hline Azithromycin+Antacid & Absorption of Azithromycin is reduced by Antacid & $1(1.9)$ \\
\hline Azithromycin+Digoxin & Plasma concentration of Digoxin is increased by Azithromycin & $3(5.6)$ \\
\hline Salbutamol & Prescription error (dosage missing) & $1(1.9)$ \\
\hline Aminophylline & Over-dose for indication & $1(1.9)$ \\
\hline Antacid & Constipation & $1(1.9)$ \\
\hline Aminophylline+Ciprofloxacin & Plasma concentration of Aminophylline is increased by Ciprofloxacin & $4(7.5)$ \\
\hline Aspirin, $75 \mathrm{mg}$ & Triggers bronchospasm & $1(1.9)$ \\
\hline Methyldopa+Furosemide & Enhanced hypotensive effect when Furosemide is given with Methyldopa & $1(1.9)$ \\
\hline IV Hydrocortisone & Prescription error (dosage missing) & $1(1.9)$ \\
\hline Aminophylline+Cimetidine & Cimetidine inhibits metabolism of Aminophylline (Increased plasma concentration) & $2(3.7)$ \\
\hline Aminophylline+Hydrocortisone & Plasma concentration of Aminophylline is increased by Hydrocortisone & $9(16.7)$ \\
\hline Artesunate+Vitamin C & Vitamin $\mathrm{C}$ inhibits the oxidation of Artemisinin derivatives & $1(1.9)$ \\
\hline Aminophylline+Erythromycin & Plasma concentration of Aminophylline is increased by Erythromycin & $5(9.3)$ \\
\hline Artemether/lumefantrine+Vitamin C & Vitamin $C$ inhibits the oxidation of Artemisinin derivatives & $11(20.4)$ \\
\hline Methyldopa & No direction for use & $1(1.9)$ \\
\hline Methyldopa+Lisinopril & Enhanced hypotensive effect when Lisinopril is given with Methyldopa & $1(1.9)$ \\
\hline Diclofenac & Triggers bronchospasm & $3(5.6)$ \\
\hline IM Metamizole & Triggers bronchospasm and has potential haematologic toxicity & $2(3.7)$ \\
\hline Cimetidine+Metronidazole & Absorption of oral Metronidazole is inhibited by Cimetidine & $1(1.9)$ \\
\hline Dihydroartemisinin/Piperaquine+Vitamin C & Vitamin C inhibits the oxidation of Dihydroartemisinin & $2(3.7)$ \\
\hline Artemether/lumefantrine+Cimetidine & Cimetidine inhibits the metabolism of Artemether/lumefantrine & $1(1.9)$ \\
\hline
\end{tabular}




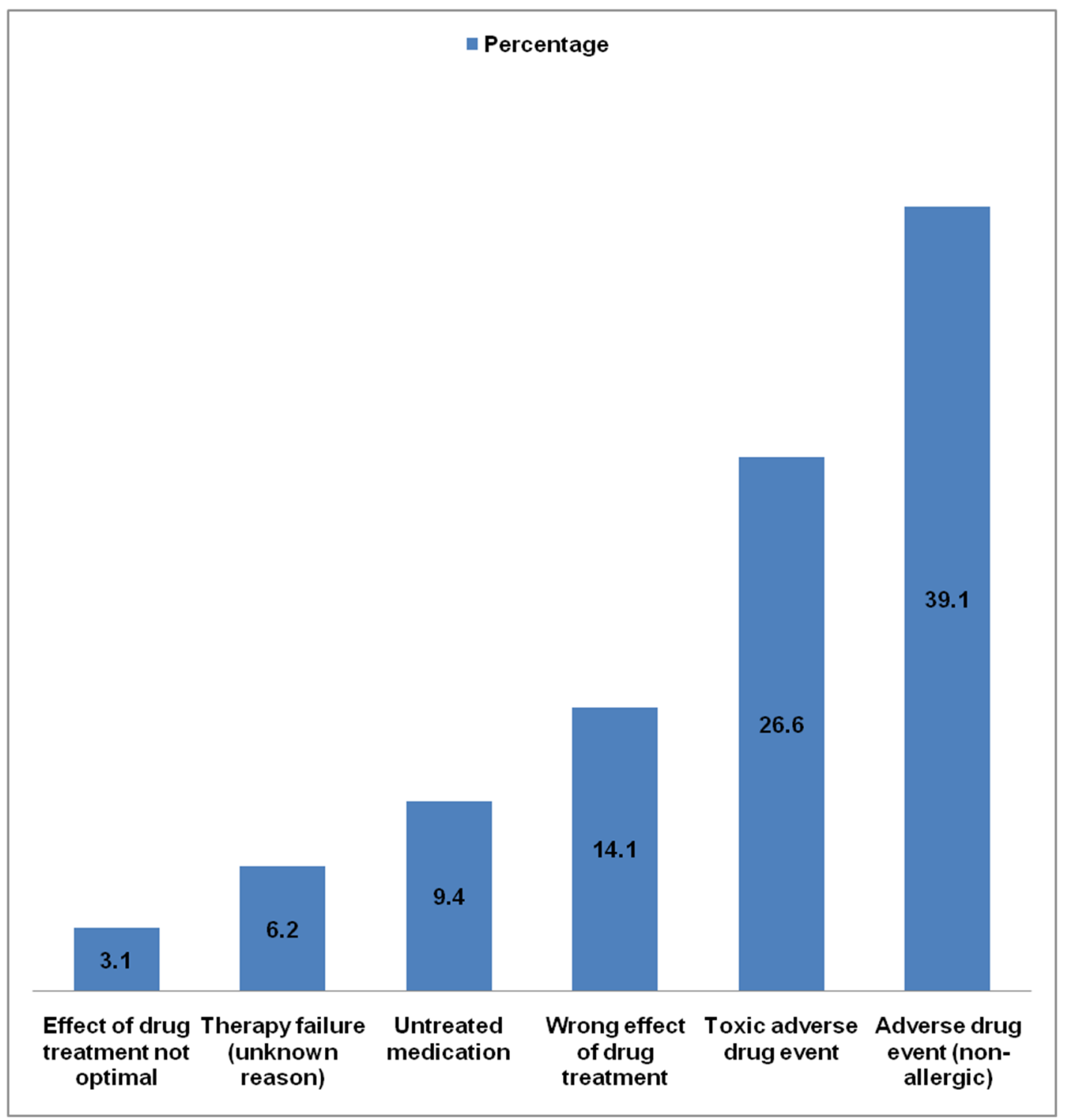

Fig. 1: Type of drug therapy problem

Table 3: Cause of drug therapy problems

\begin{tabular}{lc}
\hline Variables & n (\%) \\
\hline Drug Selection & $9(14.1)$ \\
Inappropriate drug & $1(1.6)$ \\
No indication for drug & $42(65.6)$ \\
Inappropriate combination & $2(3.1)$ \\
Too many drugs for indication & $2(3.1)$ \\
More cost-effective drugs available & $4(6.2)$ \\
Synergistic or preventive drug required & $1(1.6)$ \\
New indication presented & $1(1.6)$ \\
Dose Selection & $2(3.1)$ \\
Drug dose too high & $2(3.1)$ \\
No therapeutic drug monitoring & $3(4.7)$ \\
Pharmacokinetic problem & $6(9.4)$ \\
Drug Use Process & $6(9.4)$ \\
The under used or administered & \\
Prescribing error (information wrong or missing) & \\
Patient & \\
Patient forgets to take drug & $2(3.1)$ \\
Patient uses unnecessary drug & $1(1.6)$ \\
\hline
\end{tabular}


Table 4: Type of intervention

\begin{tabular}{|c|c|}
\hline Variables & n (\%) \\
\hline No intervention & $48(75.0)$ \\
\hline \multicolumn{2}{|l|}{ Prescriber level } \\
\hline Prescriber asked for information & $1(1.6)$ \\
\hline \multicolumn{2}{|l|}{ Drug level } \\
\hline \multicolumn{2}{|l|}{ Drug Changed to: } \\
\hline Aminophylline+Salbutamol & $1(1.6)$ \\
\hline Hydrochlorothiazide & $1(1.6)$ \\
\hline Seretide+Ventolin & $2(3.1)$ \\
\hline Tabs. Augmentin & $1(1.6)$ \\
\hline Salbutamol & $1(1.6)$ \\
\hline Cefixime & $1(1.6)$ \\
\hline \multicolumn{2}{|l|}{ Dosage changed to: } \\
\hline Aminophylline 100 mg daily & $1(1.6)$ \\
\hline \multicolumn{2}{|l|}{ Instructions for use changed to: } \\
\hline IV hydrocortisone $100 \mathrm{mg}$ thrice daily for $7 \mathrm{~d}$ & $2(3.1)$ \\
\hline \multicolumn{2}{|l|}{ Drug Stopped: } \\
\hline Azithromycin+Digoxin & $1(1.6)$ \\
\hline Aminophylline & $1(1.6)$ \\
\hline Ciprofloxacin+Aminophylline & 1 (1.6) \\
\hline Methyldopa+Furosemide & $1(1.6)$ \\
\hline \multicolumn{2}{|l|}{ New drug started: } \\
\hline Lisinopril+Furosemide & $1(1.6)$ \\
\hline
\end{tabular}

Table 5: Outcome of intervention

\begin{tabular}{ll}
\hline Variables & n (\%) \\
\hline Outcome of intervention unknown & $49(76.6)$ \\
Problem totally solved & $2(3.1)$ \\
Problem partially solved & $10(15.6)$ \\
No need or possibility to solve problem & $3(4.7)$ \\
\hline
\end{tabular}

Table 6: Association between intervention and institution

\begin{tabular}{|c|c|c|c|c|c|c|c|}
\hline & & \multicolumn{6}{|c|}{ Institution } \\
\hline & & UNTH & Medical centre & Total & $\chi^{2}$ & df & P-value \\
\hline \multirow[t]{3}{*}{ Intervention } & Yes & 14 & 2 & 16 & 6.323 & 1 & $* * 0.012$ \\
\hline & No & 25 & 23 & 48 & & & \\
\hline & Total & 39 & 25 & 64 & & & \\
\hline
\end{tabular}

Phi $=-0.314$

Table 7: Association between "outcome of intervention" and institution

\begin{tabular}{|c|c|c|c|c|c|c|c|}
\hline & & \multicolumn{6}{|c|}{ Institution } \\
\hline & & UNTH & Medical Centre & Total & $\chi^{2}$ & df & P-value \\
\hline \multirow[t]{3}{*}{ Known Outcome of Intervention } & Yes & 15 & 0 & 15 & 12.559 & 1 & $* *<0.001$ \\
\hline & No & 24 & 25 & 49 & & & \\
\hline & Total & 39 & 25 & 64 & & & \\
\hline
\end{tabular}

Phi $=-0.443$

\section{DISCUSSION}

In this study, a total of 53 drug therapy problems (DTPs) were identified among asthmatic patients receiving care over the past $15 \mathrm{y}$. Other studies have identified similar DTPs. Khan et al. [8] identified 91 DTPs in 80 asthmatics patients, Nascimento et al. [9] identified 380 DTPs in a period of two years, Root et al. [10] identified 88 DTPs from 40 patients. The difference in the number of DTPs encountered is probably due to differences in research design in terms of patients' type, hospital types, duration of the studies and nature of data collected.

Various drug combinations were responsible for DTPs which may have resulted to therapy failure or adverse drug reactions. The use of artemether-lumefantrine with vitamin $\mathrm{c}$ and aminophylline with hydrocortisone constituted the major drug therapy problems in this study. Ganiyu et al. [11] demonstrated in vivo ascorbic acid impairs the activity of artemether in the clearance of Plasmodium berghei.
Aminophylline and hydrocortisone drug combinations could lead to increased plasma concentration of aminophylline by the hydrocortisone. This is supported by a study conducted in Italy on the effects of hydrocortisone and aminophylline on the aggregation of equine platelets in vitro [12].

Majority of the identified DTPs were due to adverse reactions $(65.7 \%)$. Most of the respondents were below $60 \mathrm{y}$ of age, female and taking more than two medications. This is line with the study by Vervolet and Durham which concluded that adverse drug reactions occur mainly in young and middle-aged adults and are twice common in women [13]. Also, the use of multiple medications predisposes patients to adverse drug reactions [14]. Most of the patients in this study were on more than seven drugs. Some of these medications may also predispose the patients to other disease states as a study showed that the duration of therapy with beta- 2 agonists positively correlated with the incidence of hypertension [15]. 
Our findings establish that inappropriate drug combinations were the major cause of drug therapy problems. This contrasts that obtained in a study on asthma therapy-related problems in adult Mediterranean Croatian patients were about $40 \%$ of the drug therapy problems were due to non-adherence to medication $(66 \%)$ [16]. However, in another study by Khan et al., most DTPs (48.75\%) were from potential drug interactions [8]. Patients' poor knowledge on asthma and unfavorable attitudes towards their disease might also be responsible for undesirable drug interactions, especially with over-the-counter drugs [17]. Pharmacists can help in the right choice of drugs and possible combinations. Their counselling can improve patient adherence and the outcome of therapy [18].

Inappropriate drug selection and combination were the major causes of DTPs in this study which is consistent with a number other studies [19, 20-22]. Inappropriate drug selection may be due to inappropriate prescribing. Inappropriate prescribing may lead to increased asthma-related deaths which are totally preventable. Asthma patients in UK were at risk of a potentially life-threatening asthma attack due to unsafe prescribing [22].

About three-quarter of the DTPs had no documented interventions which might have stemmed from poor attitudes to documentation and poor patient-care approach. Of the few interventions documented, only a quarter had known intervention outcomes. Poor drug history documentation may lead to medication errors [23]. Health professionals should document appropriately to minimize or eliminate medication errors. Pharmacists' participation in medication history documentation might significantly increase the frequency and depth of medication history information documented [24]. UNTH had more interventions and known outcomes of interventions than Medical Centre. This may be because UNTH is a tertiary hospital, has a respiratory clinic, consultant pulmonologists and registrars with perhaps, better management and documentation protocols.

Our study had some limitations. The approach used to identify and classify DTPs was based on a review of medical records. Thus, there was no direct contact with the asthmatic patients. Also, due to improper or lack of documentation, few folders were pulled out for the study. Some of the patients' folders that were made available lacked sufficient information. These might have limited the information obtained.

We recommend that physicians and other healthcare providers should ensure proper asthma care to avoid therapy problems and complications. They should adhere to the recommended guidelines and utilize reference books to minimize errors in prescription, dispensing or administration. Patients should be effectively counselled to ensure that they fully understand how and when to take their medications.

Proper documentation system in health institutions should be encouraged. Physicians should improve in documenting on patients' folders. This could be helpful for references and research. More professional librarians should be employed in Medical Records for expert documentation and easy assessment of files when needed. More studies on drug therapy problems in asthma should be conducted in Nigeria as there is a paucity of data.

\section{CONCLUSION}

Adverse reactions were identified as the drug therapy problems among asthmatics. Inappropriate drug selection was the major cause of drug therapy problems. Most of the DTPs had no interventions. The documented interventions included stopping of the drugs, change of drugs or dosage, change of instructions for use and starting of new drugs. The outcomes of most of the interventions were not known. UNTH had more interventions with known outcomes than the University of Nigeria Medical Centre.

\section{AUTHORS CONTRIBUTIONS}

KCA conceived and designed the study and participated in the data analysis; ACO was involved with the data acquisition and drafting of the article; CGA drafted the article; CVU approved the final version to be submitted, although all authors read the drafted manuscript.

\section{CONFLICTS OF INTERESTS}

All authors have no conflicts of interest to declare

\section{REFERENCES}

1. Global Initiative for Asthma. Global Strategy for Asthma Management and Prevention; 2014. Available from: http://www.ginasthma.org. [Last accessed on 11 Aug 2017]

2. Global Initiative for Asthma. Pocket guide for Physician and Nurses 2014. Based on Global Strategy for Asthma Management and Prevention; 2014. Available from: http://www.ginasthma.org. [Last accessed on 12 Aug 2017]

3. Centres for Disease Control and Preventions (CDC), National Asthma Control Programs, Asthma Fast Facts; 2016. Available from: http://www.cdc.gov/asthma//asthma-fast-fact. [Last accessed 09 Mar 2017]

4. Global Asthma Network (GAN). The Global Asthma Report: Asthma in Low-and Middle-Income Countries; 2014. Available from: http://www.globalasthmareport.org/ [Last accessed 07 Mar 2017]

5. Roti. At least 15 million Nigerians are suffering from Chest related Diseases-Expert. Information Nigeria; 2012. Available from: https://www.informationng.com/2012/12/at-least-15million-Nigerians-are suffering-from-chest-relted-diseasesexpert.html. [Last accessed on 19 Apr 2017]

6. Robert JC, Linda MS, Peter CM. Chapter 5: Drug Therapy Problems. Available from: http://accesspharmacy. mhmedical.com/book.aspx?bookid=491. [Last accessed on 24 Apr 2017]

7. Pharmaceutical Care Network Europe Foundation. PCNE Classification for Drug-Related (revised 14-01-10 vm) V6.2; 2010. Available from: http://www.pcne.org/workinggroups/ 2/drug-related-problems. [Last accessed on 25 Apr 2016]

8. Khan AU, Ali I, Zafar R, Khalil A. Identification of drug-related problems and pharmacist's interventions in asthmatic patients at a private tertiary care facility-Pakistan. J Res Pharm Pract 2015;6:33-7.

9. Nascimento YA, Carvalho WS, Acurcio FA. Drug-related problems observed in a pharmaceutical care service, problems observed in a pharmaceutical care service, Belo Horizonte, Brazil. Braz J Pharm Sci 2009;45:321-30.

10. Root R, Phelps P, Brummel A, Else C. Implementing a pharmacist-led medication management pilot to improve care transitions. Innovations Pharm 2012;3:2.

11. Ganiyu KA, Akinleye MO, Fola TA. Study of the effect of ascorbic acid on the antiplasmodial activity of artemether in plasmodium Berghei infected mice. J Appl Pharm Sci 2012;2:96-100.

12. Casella S, Giudice E, Giannetto C, Marafioti S, Piccione G. Effects of hydrocortisone and aminophylline on the aggregation of equine platelets in vitro. J Vet Sci 2011;12:215-9.

13. Vervolet D, Durham S. Adverse reactions to drugs. Br Med J 1998;16:1511-4.

14. Cokaric M, Popovic SG, Bacic VV. Asthma therapy-related problems in adult mediterranean croatian patients. World J Pharm Sci 2015;2:2321-3310.

15. Rina A, Eff Y. The incidence of hypertension in asthma patients who treated with beta-2 agonists bronchodilators. Int J Pharm Pharm Sci 2017;9:181-4.

16. Rahmawati F, Pramantara DP, Rohmah W, Sulaiman SAS. Polypharmacy and unnecessary drug therapy on geriatric hospitalized patients in yogyakarta hospitals, Indonesia. Int J Pharm Pharm Sci 2009;1:6-11.

17. Muthukumar A, Sundara GR. A prospective clinical study on disease knowledge and medication adherence pattern among asthmatic patients in tertiary care hospital in a tirupur population. Asian J Pharm Clin Res 2017;10:388-91.

18. Sari CP, Hakim L, P Putu DI. Role of pharmacist in counselling asthma to improve patient adherence in Yogyakarta. ICPPS; 2017. p. 16-20.

19. Odili VU, Egiebor BO, Oparah AC. Identification of drug therapy problems in patients with diabetes treated in a secondary care facility in Benin city. Nig J Pharm Res 2011;9:72-81. 
20. Blix HS, Viktil KK, Reikvam S, Moger TA, Hjemaas BJ, Pretsch P, et al. Walseth the majority of hospitalised patients have drugrelated problems: results from a prospective study in general hospitals. Eur J Clin Pharmacol 2004;60:651-8.

21. Suleiman IA, Eniojukan JF, Eze I. Evaluating pharmaceutical care documentation among pharmacists in Nigeria. West Afr J Pharm 2012;23:69-76.

22. Lewis C, Humphreys E, Chisholm A, Carter V, Price D. Evidence of poor prescribing in asthma care. Respiratory Effectiveness Group Asia-Pacific summit, Singapore. Analysis conducted by Asthma UK using an Optimum Patience Care Research
Database (www.optimumpatientcare.org), supplied through the Respiratory Effectiveness Group (www.effectiveness evaluation.org) initiative; 2015.

23. Richards M, Espitalier-Noel D, Stacey H, Thomerson J, Butt T. Poor drug history documentation in admission medical notes: clerking prompts and junior doctor education alone do not significantly reduce errors. Acute Med 2015;14:104-10.

24. Yusuff KB, Tayo F, Aina BA. Pharmacists' participation in the documentation of medication history in a developing setting: an exploratory assessment with new criteria. J Pharm Pract 2010;8:139-45. 